\title{
CARBON SEQUESTRATION ASSESSMENT OF THE ORCHARDS USING SATELLITE DATA
}

\author{
Yannawut Uttaruk ${ }^{1}$, Teerawong Laosuwan ${ }^{1,2}$ \\ 1 Faculty of Science, Mahasarakham University, Katarawichai, Mahasarakham, 44150, Thailand \\ 2 Space Technology and Geoinformatics Research Unit, Faculty of Science, Mahasarakham University, \\ Mahasarakham, 44150, Thailand \\ Corresponding author's email: teerawong@msu.ac.th
}

Received: 2016.09.24

Accepted: 2016.10.23

Published: 2017.01.01

\begin{abstract}
This study aimed to estimate above-ground carbon sequestration of orchards using satellite data. The research methodology analyzed the relationship between the amount of above-ground carbon sequestration and vegetation indices from the data obtained from LANDSAT 8 OLI including (1) Difference Vegetation Index (DVI), (2) Green Vegetation Index (GVI), (3) Simple Ratio (SR), (4) Normalized Difference Vegetation Index (NDVI), and (5) Transformed Normalized Difference Vegetation Index (TNDVI) in order to find out the most appropriate equation to estimate aboveground carbon sequestration of the orchards in the study area at Sang Kho sub district, Phu Phan district, Sakon Nakhon province in northeast Thailand. The study results found that the relationship between the amount of above-ground carbon sequestration and the most appropriate index relating to vegetation was TNDVI. At any rate, TNDVI had the relationship equation $\mathrm{y}=0.226 \mathrm{e}^{0.039 \mathrm{x}}$ and coefficient of determination $\mathrm{R}^{2}=0.877$, which represented the amount of above-ground carbon sequestration in the study area in a total of 40.86 tons per hectare.
\end{abstract}

Keywords: carbon sequestration assessment, satellite data, vegetation indices

\section{INTRODUCTION}

The earth receives energy from the sun in form of light energy. Some of the energy will reflect back to the outside earth in form of thermal energy. And some part of the thermal energy will be absorbed by greenhouse gas that is in the natural atmosphere in a less amount. This thermal energy absorbed by greenhouse gas will create warmth to the earth and enables creatures to live in this earth. But if there are too much greenhouse gas, it will result in sequestration and reflection of heat back down to the earth, which is a cause of global warming. All of greenhouse gases cause by human activities. The most important gas is carbon dioxide $\left(\mathrm{CO}_{2}\right)$ [Litynski et al., 2006; Lal, 2007; Wasun et al., 2010]. In order that, $\mathrm{CO}_{2}$ will be released into the atmosphere by various processes such as burning combustion, deforestation and etc. Meanwhile, the growth of trees by the process of photosynthesis causes carbon dioxide absorbance of forest and converted into biomass above ground (stem, branches, leaves) and underground (roots) [Ogawa et al., 1965; Senpaseuth et al., 2009] so that the carbon was held in the trees until the trees were cut out of the areas. This process is called «carbon sequestration», which is regarded as the most effective in reducing carbon dioxide [Teerawong and Pornchai 2014; Teerawong and Yannawut 2016].

At any rate, the estimation of carbon sequestration of forests usually requires a high budget due to the space exploration is difficult to take action comprehensively. Currently, the technology of Remote Sensing is being applied to assist in estimation of above-ground carbon sequestration. Due to the data from satellites provided the value of reflectivity at different wavelengths so that the 
evaluation of above-ground carbon sequestration in forest area could be implemented quickly with lower budget [Liaghat and Balasundram, 2010; Gomasathit et al., 2011; Laosuwan et al., 2011; Odindi et al., 2015]. Remote sensing is considered as a modern technology that is increasingly important due to the data obtained from satellites has evolved rapidly in terms of recording and data analysis methods, especially sensor record system that has developed in terms of spatial resolution and spectral resolution so that it contributed to a wide range of applications in various fields increasingly. Moreover, the data from satellites is currently accepted widely in the efficiency to monitor changes in events caused by natures and human actions in due time [Campbell, 1996; Lu, et al., 2002; Laosuwan et al., 2011; Patel et al., 2007; Schlerf and Alzberger, 2005; Samaniego and Schulz, 2009; Senpaseuth et al., 2009; Arbind, 2013; Rees, 2013].

In Thailand, most studies were about estimation of carbon sequestration of forests and forestry plantations. There are still no studies about the estimation of above-ground carbon sequestration of orchards. Therefore, this study aimed to study above-ground carbon sequestration with the data from LANDSAT 8 OLI of the orchards at Sang Kho sub district, Phu Phan district, Sakon Nakhon province in northeast Thailand.

\section{MATERIALS AND METHODS}

\section{Data collection and study area}

This study used the data from Landsat 8 OLI in Path 127 Row 49 that recorded the data on 6 January 2015. The data obtained from the satel- lite can be downloaded from The US Geological Survey (USGS) on the website http://glovis. usgs.gov/. For an area of the orchards belonging to eleven farmers at Sang Kho sub district, Phu Phan district, Sakon Nakhon province in northeast Thailand. These areas were selected as a pilot area in this study in a total area of 11.55 hectare (Figure 1).

\section{Primitive data preparation}

In data preparation before analyzing, the value of Top of Atmosphere (ToA) Reflectance of the data obtained from Landsat 8 OLI was adjusted for data accuracy. It was implemented in two phases:

1) Process of Convert Digital Number to Radiance Values and

2) Process of Convert Radiance to ToA Reflectance. The researchers referred these two operational processes from Equation 1 and Equation 2 as below [Teerawong and Pornchai, 2014; Teerawong and Yannawut, 2016].

$$
L_{\lambda}=\text { Grescale }^{*} \text { Qcal }+ \text { Brescale }
$$

where:

$$
\text { Grescale }=\frac{\operatorname{LMAX}_{\lambda}-\operatorname{LMIN}_{\lambda}}{\text { Qcalmax }- \text { Qcalmin }}
$$

$$
\begin{gathered}
\text { Brescale }=\operatorname{LMIN}_{\lambda}-\left[\operatorname{LMAX}_{\lambda}-\operatorname{LMIN}_{\lambda} /\right. \\
\text { / Qcalmax }- \text { Qcalmin }] \times \text { Qcalmin }
\end{gathered}
$$

where: $L_{\lambda}$ - spectral radiance at the sensor's aperture $\left[\mathrm{W} /\left(\mathrm{m}^{2} \mathrm{sr} \mu \mathrm{m}\right)\right]$

Qcal - quantized calibrated pixel value [DN]

Qcalmin - minimum quantized calibrated pixel value corresponding $\operatorname{LMIN}_{\lambda}$

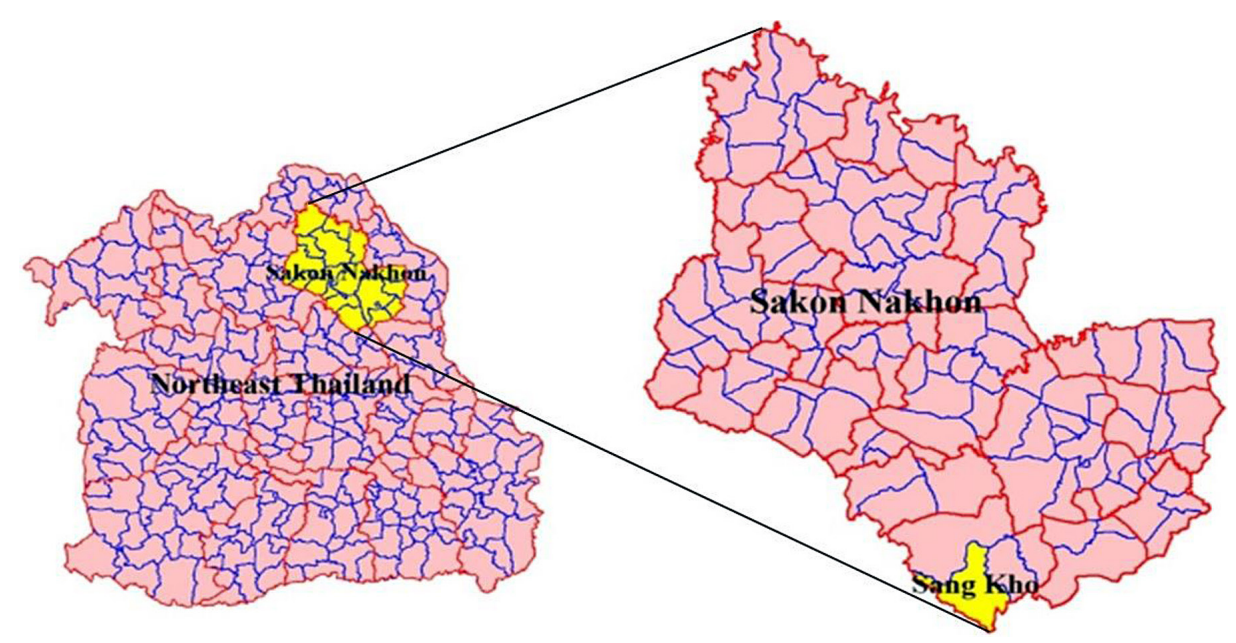

Figure 1. The study area 
Qcalmax - maximum quantized calibrated pixel value corresponding $\operatorname{LMAX}_{\lambda}$ $L M I N_{\lambda}-$ spectral at sensor radiance that is scaled to Qcalmin [W/( $\left.\left.\mathrm{m}^{2} \mathrm{sr} \mu \mathrm{m}\right)\right]$

$L M A X_{\lambda}-$ spectral at sensor radiance that is scaled to Qcalmax $\left./ \mathrm{W} /\left(\mathrm{m}^{2} \mathrm{sr} \mu \mathrm{m}\right)\right]$

Grescale - band specific rescaling gain factor $\left[\left(\mathrm{W} /\left(\mathrm{m}^{2} \mathrm{sr} \mu \mathrm{m}\right)\right) / \mathrm{DN}\right]$

Brescale - band specific rescaling bias factor $\left[\mathrm{W} /\left(\mathrm{m}^{2} \mathrm{sr} \mu \mathrm{m}\right)\right]$

$$
\rho_{\lambda}=\frac{\pi \times L_{\lambda} \times d^{2}}{E_{S U N_{\lambda}} \times \cos \theta_{s}} \text { (2) }
$$

where: $\rho_{\lambda}$-Unitless planetary reflectance

$L_{\lambda}$ - Spectral radiance at sensor's aperture $\left(\mathrm{Wm}^{-2} \mathrm{sr}^{-1} \mu \mathrm{m}^{-1}\right)$

$d$ - Earth-sun distance in astronomical units

$E_{S_{U N} N_{\lambda}}$ - Mean solar exoatmospheric irradiances

$\theta_{s}$ - Solar zenith angle

\section{Analysis of the data from Landsat $8 \mathrm{OLI}$ Satellite}

Difference Vegetation Index (DVI) for DVI is a difference between the reflectance of vegetation approaching to 1 representing it has a high value of vegetation. In contrast, the reflection of the vegetation approaching to 0 has a low value of vegetation. The researchers referred the DVI calculation from Equation 3 [Tucker, 1979; Agapiou et al., 2012].

$$
D V I=N I R-R
$$

where: $N I R$ - Near infrared band of Landsat 8 OLI $R$ - Red band of Landsat 8 OLI

Green Vegetation Index (GVI) for GVI is a vegetation index that is used to monitor the difference in the absorption of chlorophyll in plants. Each season has different vegetation growth so it has different reflection of the wave as well. The result of the calculation was the index values in the range of -1 to +1 . For the analysis to find out the value of GVI in this study, the researchers referred to Equation 4 [Gandia et al., 2004; Agapiou et al., 2012].

$$
\begin{gathered}
G V I=(0.2848 \times B 1)-(0.2435 \times B 2)-(0.5436 \times B 3)+ \\
(0.7243 \times B 4)+(0.0840 \times B 5)-(0.1800 \times B 7)
\end{gathered}
$$

where: $B 1, B 2, B 3, B 4, B 5, B 7$ - band of Landsat 8 OLI
Simple Ratio (SR) for SR is a simple vegetation index and a simple ratio of the two wavelengths by bringing the near-infrared wavelength to be divided by the visible red wavelength. In this study, the researchers referred from Equation 5 [Jordan, 1969; Agapiou et al., 2012].

$$
S R=N I R / R
$$

Normalized Difference Vegetation Index (NDVI) for NDVI is a vegetation index used to determine the difference in the absorption of chlorophyll in plants. Each season has different vegetation growth so it has different reflection of the wave as well. As a result, it is commonly used nowadays. The result of the calculation of the index values was in arrange of -1 and +1 . The value of NDVI would be less than 0 on the water ground, in a range of $0-0.1$ on the clear ground and more than 0.1 on the area with plants covered. The analysis to find out NDVI values in this study, the researchers referred to Equation 6 [Rouse, 1974; Agapiou et al., 2012; Laosuwan et al., 2016].

$$
N D V I=\frac{N I R-R E D}{N I R+R E D}
$$

where: $N I R-$ Near infrared band of Landsat 8 OLI $R$ - Red band of Landsat 8 OLI

Transformed Normalized Difference Vegetation Index (TNDVI) for TNDVI index is an index measuring the amount of green biomass and composition of chlorophyll in plants. The value of 0.5 was plus to the value of NDVI in order to avoid the negative value and used a square root with that value. For the analysis to find out TNDVI in this study, the researchers referred to Equation 7 6 [Tucker, 1979; Farooq, 2011].

$$
T N D V I=((N I R-R E D) /(N I R+R E D)+0.5)(7)
$$

where: NIR - Near infrared band of Landsat 8 OLI

$$
R \text { - Red band of Landsat } 8 \text { OLI }
$$

\section{Finding out fractional cover coefficient}

At this stage, the fractional cover coefficient of DVI, GVI, SR, NDVI and TNDVI would be found out with Equation 8 [Teerawong and Pornchai, 2014; Teerawong and Yannawut, 2016]. Then, the relationship of statistical data between the amount of above-ground carbon sequestration (dependent variable) and vegetation indices by using pixel at the same position of sample plots (size $20 \times 20$ meters in a total of 22 plots spread- 
ing around the study area) that were collected the field data by analyzing coefficient of determination to explore the relationship between dependent variables and independent variables to be information for decisions in selecting appropriate independent variables to create equations to estimate above-ground carbon sequestration.

$$
F C=\frac{\left(V I-V I_{\text {open }}\right)}{\left(V I_{\text {canopy }}-V I_{\text {open }}\right)} \times 100
$$

where: $F C$ - Tree canopy fractional cover

$V I$ - Vegetation index

$V I_{\text {open }}$ - Vegetation index of open areas

$V I_{\text {canopy }}^{\text {open }}-$ Vegetation index of tree canopy

\section{RESULTS}

\section{Primitive data preparation}

In this study provided the result of information from Landsat 8 OLI Satellite which passed

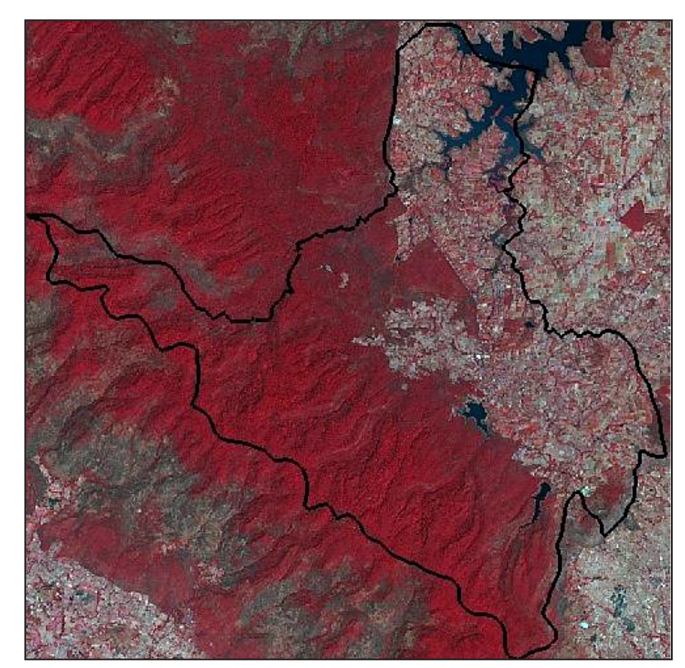

Figure 2. Before TOA through the adjustment process as shown in Figures 2 and 3 .

\section{The results of analyzing the data from Landsat 8 OLI Satellite}

The results of finding out the relationship between the amount of above-ground carbon sequestration and the indexes related to vegetation from the images data of LANDSAT 8 OLI included DVI, GVI, SR, NDVI and TNDVI on 6 January 2015 can be shown in Table 1 .

\section{The result of finding out the value of coefficient of fractional cover}

The result of finding out the value of coefficient of fractional cover of Landsat 8 OLI Satellite which passed through the process of DVI, GVI, SR, NDVI and TNDVI can be shown in Table 2.

The relationship of the statistical data was conducted by bringing the data from Landsat 8 OLI Satellite which passed through the analysis

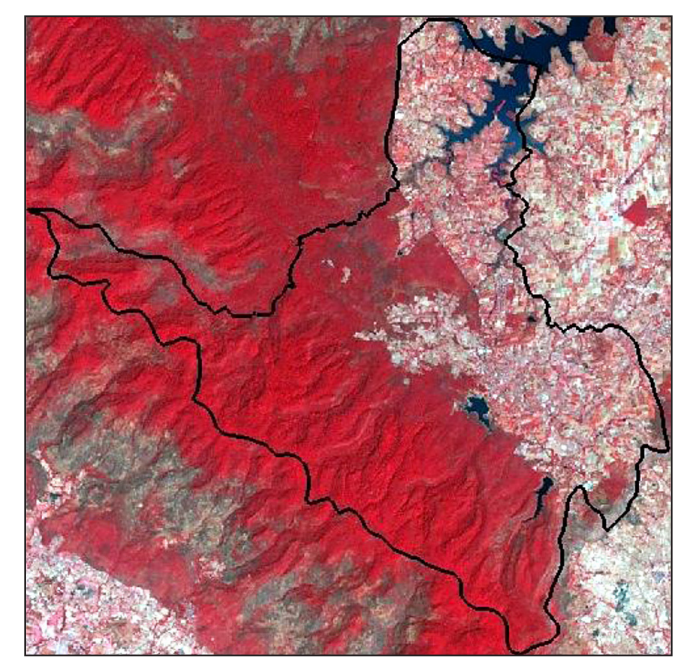

Figure 3. After TOA

Table 1. The results of analyzing the data from Landsat 8 OLI Satellite

\begin{tabular}{|c|c|c|c|c|c|c|c|c|}
\hline No. & Owner & tC_area & tC_area_Pixel & GVI & IR-R & IR_R & NDVI & TNDVI \\
\hline 1 & IN03001 & 33.47 & 18.83 & 20.39 & 18.83 & 25.88 & 28.14 & 28.24 \\
\hline 2 & IN03002 & 23.35 & 13.13 & 17.19 & 18.23 & 11.67 & 13.10 & 13.19 \\
\hline 3 & IN03003 & 41.63 & 23.42 & 31.15 & 32.14 & 27.25 & 28.99 & 29.18 \\
\hline 4 & IN03004 & 02.27 & 1.28 & 06.11 & 05.70 & 07.67 & 07.77 & 07.73 \\
\hline 5 & IN03006 & 16.39 & 9.22 & 12.23 & 11.93 & 11.68 & 13.60 & 13.73 \\
\hline 6 & IN03007 & 72.35 & 40.70 & 32.52 & 30.86 & 38.68 & 43.00 & 43.21 \\
\hline 7 & IN03008 & 04.14 & 2.33 & 04.05 & 03.83 & 04.63 & 05.23 & 05.31 \\
\hline 8 & IN03009 & 15.517 & 8.72 & 16.28 & 18.14 & 13.67 & 14.09 & 14.15 \\
\hline 9 & IN03010 & 90.52 & 50.91 & 52.32 & 49.48 & 67.56 & 66.05 & 65.57 \\
\hline 10 & IN03011 & 55.05 & 30.97 & 11.18 & 10.43 & 15.60 & 17.15 & 17.27 \\
\hline 11 & IN03012 & 53.71 & 30.22 & 17.06 & 16.60 & 19.91 & 18.03 & 17.82 \\
\hline
\end{tabular}


Table 2. Result of finding out the value of coefficient of fractional cover of Landsat 8 OLI

\begin{tabular}{|c|c|c|c|c|}
\hline Correlation & RMSE & RMSE\% & Bias & Bias \% \\
\hline GVI & 8.55 & 40.94 & -0.84 & -4.01 \\
\hline IR-R & 9.17 & 43.93 & -1.23 & -5.90 \\
\hline IR/R & 8.35 & 39.97 & 1.32 & 6.31 \\
\hline NDVI & 8.48 & 40.59 & 2.31 & 11.07 \\
\hline TNDVI & 8.44 & 40.43 & 2.33 & 11.17 \\
\hline
\end{tabular}

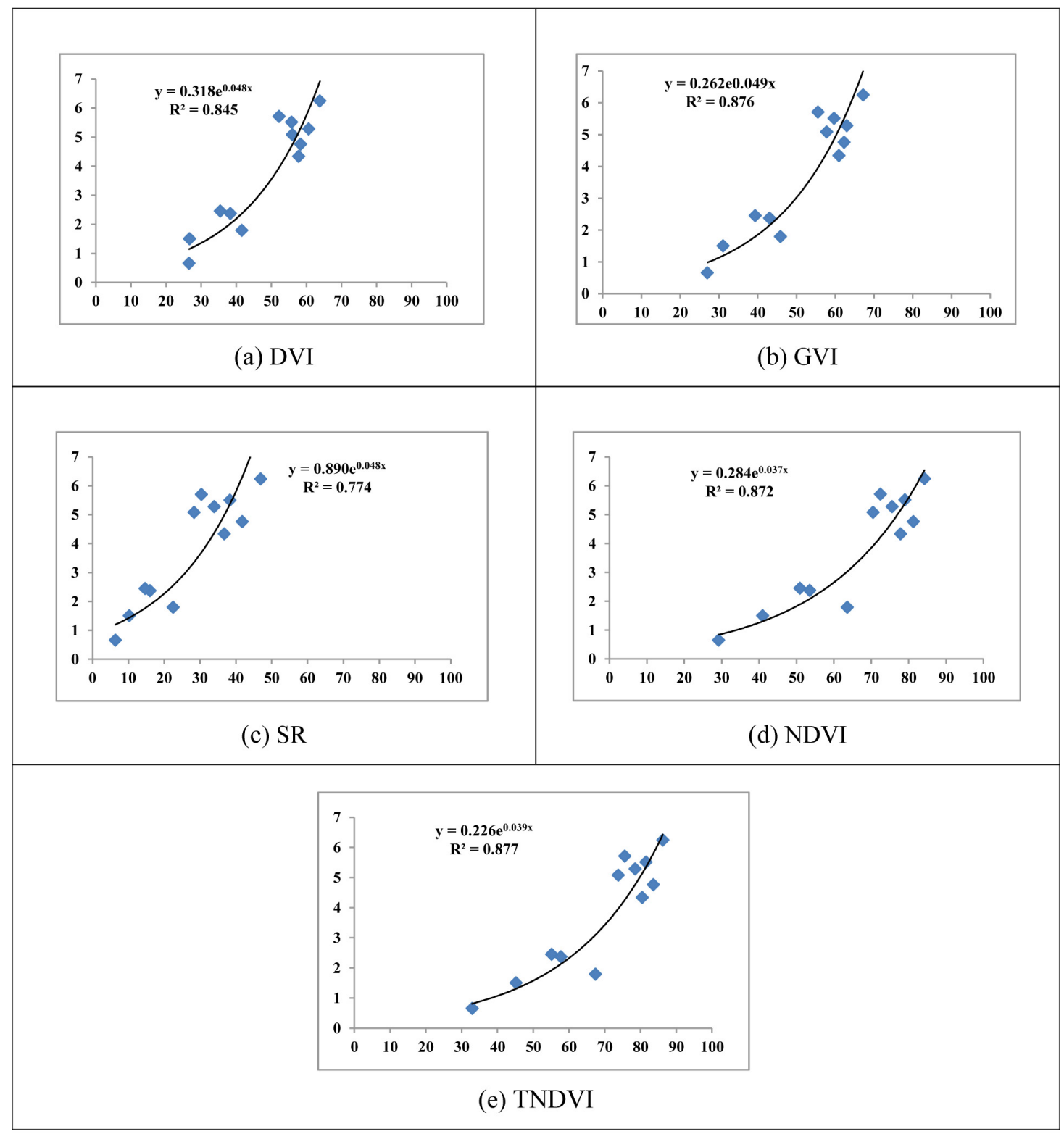

Figure 4. Relationship of the statistical data

process to analyze in order to find out the relationships with the field data to create equations to estimate above-ground carbon sequestration (Figure 4). The study results of the relationship between the amount of above-ground carbon sequestration and the indexes related to vegetation in the study area can be explained as follows:
1) DVI had relationship equation $y=0.318 \mathrm{e}^{0.048 \mathrm{x}}$ with coefficient of determination $\mathrm{R}^{2}=0.845$. As a result, the calculation of above-ground carbon volume was 44.19 tons per hectare.

2) GVI had relationship equation $y=0.262 \mathrm{e}^{0.049 x}$ with coefficient of determination $\mathrm{R}^{2}=0.876$. As a result, the calculation of above-ground 
carbon volume was 38.28 tons per hectare.

3) SR had relationship equation $y=0.890 \mathrm{e}^{0.048 \mathrm{x}}$ with coefficient of determination $\mathrm{R}^{2}=0.774$. As a result, the calculation of above-ground carbon volume was 39.08 tons per hectare.

4) NDVI had relationship equation $y=0.284 \mathrm{e}^{0.037 x}$ with coefficient of determination $\mathrm{R}^{2}=0.872$. As a result, the calculation of above-ground carbon volume was 40.83 tons per hectare.

5) TNDVI had relationship equation $y=$ $0.226 \mathrm{e}^{0.039 \mathrm{x}}$ with coefficient of determination $\mathrm{R}^{2}=0.877$. As a result, the calculation of above-ground carbon volume was 40.86 tons per hectare.

\section{CONCLUSSIONS}

From the study of estimation of aboveground carbon sequestration of the orchards with LANDSAT 8 OLI in Sang Kho sub district, Phu Phan district, Sakon Nakhon province in northeast Thailand can be concluded that the most appropriate method was TNDVI. As a result of TNDVI had relationship equation $y=0.226 \mathrm{e}^{0.039 \mathrm{x}}$ with coefficient of determination $\mathrm{R}^{2}=0.877$. As a result, the calculation of above-ground carbon volume was 40.86 tons per hectare. In addition, the researchers also tested the statistical validity of above-ground carbon from LANDSAT 8 OLI and field data with the Pair Sample T-test method and found that DVI, GVI, SR, NDVI and TNDVI had statistical significance with a confidence level of $95 \%$. Therefore, those who are interested can apply one out of those five equations in estimation of above-ground carbon sequestration of the orchard in other areas in Thailand onward.

\section{Acknowledgements}

This research was financially supported by Mahasarakham University. The author would like to thank Mr. Miss. Kusuma Arsasana and Miss. Siritorn Dumrongsukit for filed data collection.

\section{REFERENCES}

1. Agapiou A., Hadjimitsis D.G., Alexakis D.D. 2012. Evaluation of Broadband and Narrowband Vegetation Indices for the Identification of Archaeological Crop Marks. Remote Sens., 4, 3892-3919.

2. Arbind Kumar Shah. 2013. Remote sensing - A part of an Applied Physics. The Himalayan Physics, 4.
3. Campbell J.B. 1996. Introduction to Remote Sensing. Taylor \& Francis, London.

4. Desert. Journal of Geography and Regional Planning, 5(6), 165-172.

5. Farooq Ahmad, 2011. Spectral vegetation indices performance evaluated for Cholistan

6. Gandia S., Fernández G., García J.C., Moreno J. 2004. Retrieval of Vegetation Biophysical Variables from CHRIS/PROBA Data in the SPARC Campaing. In Proceedings of the 4th ESA CHRIS PROBA Workshop, Frascati, Italy, 28-30 April 2004, 40-48.

7. Gomasathit T., Laosuwan T., Chunpang P., Uraichun Y. 2011. The Real Experience in GIS Teaching Aid by Using GIS Open-Source Software, International Journal of Geoinformatics, 7 (4), 63-67.

8. Jordan C.F. 1969. Derivation of leaf area index from quality of light on the forest floor. Ecology, 50, 663-666.

9. Lal R. 2007. Researchable Priorities in Terrestri al Carbon Sequestration in Central Asia. In: Climate Change and Terrestrial Carbon Sequestration in Central Asia, Lal, R., B.A. Stewart, D.O. Hansen and P. Doraiswamy (Eds.). Routledge, London.

10. Laosuwan T., Uttarak P., Klinhom U., Butthep C., Samek J.H. and Skole D.L. 2011. Development of Web-GIS Application for Carbon Sequestration in Thailand, International Journal of Geoinformatics, 7 (2), 41-47.

11. Laosuwan T., Chunpang P., Sukkasena S. 2011. Development of Robotic Aerial Remote Sensing System for Field Educational Purpose, International Journal of Geoinformatics, 7 (4), 21-27.

12. Laosuwan T., Sangpradid S., Gomasathit T. and Rotjanakusol T. 2016. Application of Remote Sensing Technology for Drought Monitoring in Mahasarakham Province, Thailand. International Journal of Geoinformatics, 12 (3), 17-25.

13. Liaghat S. and Balasundram S.K. 2010. A review: The role of remote sensing in precision agriculture. Am. J. Agric. Biol. Sci., 5, 50-55.

14. Lu D., Mausel P., Brondizio E., Moran E. 2002. Assessment of atmospheric correction methods for Landsat TM data applicable to Amazon basin LBA research. Int. J. Remote Sens., 23, 2651-2671.

15. Litynski J.T., Klara S.M., McIlvried H.G. and Srivastava R.D. 2006. The United States Department of Energy's regional carbon sequestration partnerships program: A collaborative approach to carbon management. Environ. Int., 32, 128-144.

16. Ogawa H., Yoda K., Ogini K. and Kira T. 1965. Comparative Ecological Study on Three Main Type of Forest Vegetation in Thailand. Nature and Life in Southeast Asia, 4, 49-80.

17. Patel N.K., Saxena R.K., Shiwalkar A. 2007. Study of 
fractional vegetation cover using high spectral resolution data. J. Indian Soc. Remote Sens., 35, 73-79.

18. Rees W.G. 2013. Physical Principles of Remote Sensing. Cambridge University Press;

19. Rouse J.W., Haas R.H., Schell J.A., Deering D.W., Harlan J.C. 1974. Monitoring the Vernal Advancements and Retrogradation (Greenwave Effect) of Nature Vegetation; NASA/GSFC Final Report; NASA: Greenbelt, MD, USA.

20. Samaniego L., Schulz K. 2009. Supervised classification of agricultural land cover using a modified $\mathrm{k}-\mathrm{NN}$ technique (MNN) and Landsat remote sensing imagery. Remote Sens., 1, 875-895.

21. Schlerf M., Alzberger C., Hill J. 2005. Remote sensing of forest biophysical variables using HyMap imaging spectrometer data, Remote Sens. Environ, 95, 177-194.

22. Senpaseuth P., Navanugraha C., and Pattanakiat S. 2009. The Estimation of Carbon Storage in Dry Evergreen and Dry Dipterocarp Forests in
Sang Khom District, Nong Khai Province, Thailand Environment and Natural Resources Journal, 7(2), 1-11.

23. Teerawong Laosuwan \& Pornchai Uttaruk, 2014. Estimating Tree Biomass via Remote Sensing, MSAVI 2, and Fractional Cover Model. IETE Technical Review, 31(5), 362-368.

24. Teerawong Laosuwan and Yannawut Uttaruk, 2016. Estimating Above Ground Carbon Capture Using Remote Sensing Technology in Small Scale Agro Forestry Areas. Agriculture \& Forestry, 62 (2), 253-262.

25. Tucker C.J. 1979. Red and photographic infrared linear combinations for monitoring vegetation. Remote Sens. Environ., 8, 127-150.

26. Wasun Jundang, Ladawan Puangchit and Sapit Diloksumpun, 2010. Carbon Storage of Dry Dipterocarp Forest and Eucalypt Plantation at Mancha Khiri Plantation, Khon Kaen Province. Thai Journal of Forestry, 29 (3), 36-44. 